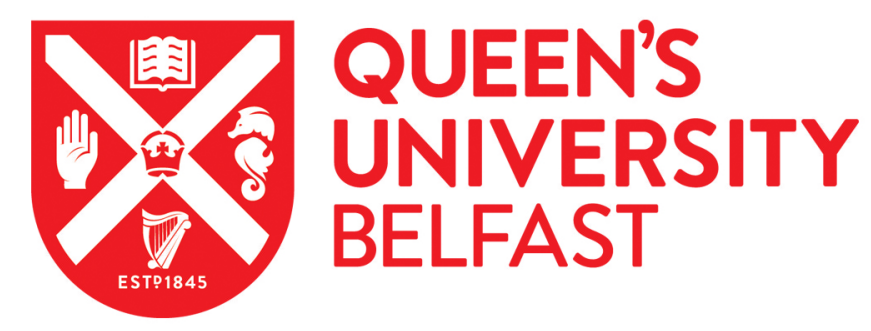

\title{
Analysis of Strongyle Egg Shedding Consistency in Horses and Factors That Affect It
}

Lester, H. E., Morgan, E. R., Hodgkinson, J. E., \& Matthews, J. B. (2018). Analysis of Strongyle Egg Shedding Consistency in Horses and Factors That Affect It. Journal of Equine Veterinary Science, 60, 113-119.

https://doi.org/10.1016/j.jevs.2017.04.006

Published in:

Journal of Equine Veterinary Science

Document Version:

Peer reviewed version

Queen's University Belfast - Research Portal:

Link to publication record in Queen's University Belfast Research Portal

Publisher rights

(C) 2017 Elsevier Inc.

This manuscript version is made available under the CC-BY-NC-ND 4.0 license http://creativecommons.org/licenses/by-nc-nd/4.0/,which permits distribution and reproduction for noncommercial purposes, provided the author and source are cited.

\section{General rights}

Copyright for the publications made accessible via the Queen's University Belfast Research Portal is retained by the author(s) and / or other copyright owners and it is a condition of accessing these publications that users recognise and abide by the legal requirements associated with these rights.

Take down policy

The Research Portal is Queen's institutional repository that provides access to Queen's research output. Every effort has been made to ensure that content in the Research Portal does not infringe any person's rights, or applicable UK laws. If you discover content in the Research Portal that you believe breaches copyright or violates any law, please contact openaccess@qub.ac.uk. 
1 Analysis of strongyle egg shedding consistency in horses and

2 factors that affect it

3

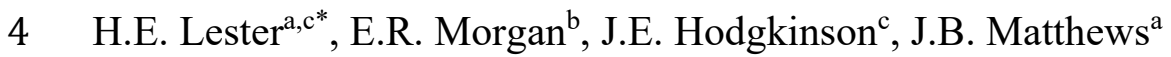

$5 \quad{ }^{a}$ Moredun Research Institute, EH26 OPZ, UK

$6{ }^{b}$ School of Veterinary Sciences, University of Bristol, BS40 5DU, UK.

$7 \quad$ Institute of Infection and Global Health, University of Liverpool, L3 5RF, UK

8

$9 \quad{ }^{*}$ Corresponding author.

10 E-mail address: lester.hannah@yahoo.com (H.E. Lester).

11 


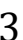

\section{Abstract}

Strongyle egg shedding consistency in horses and factors affecting consistency were investigated. Faecal samples were collected from 26 equine populations over one grazing season. Samples were collected on four 'screening' occasions (S1-S4) and FEC performed using a sensitive method (to 1 eggs per gram (epg) egg detection limit). On each screening occasion, FEC were assigned an egg shedding category: 1 ( $<50 \mathrm{epg})$ to 7 ( $>500 \mathrm{epg}$ ); and a treatment category: $<200$ epg (no treatment) or $\geq$ 200 epg (treatment). Rank changes in shedding and treatment categories between S1 and subsequent screening occasions were calculated. Factors affecting the likelihood of an individual changing shedding or treatment category were assessed using multivariable logistic regression of FEC data from horses that had not received anthelmintic during the study. In total, 573 horses were sampled at S1, 468 at S2, 417 at S3 and 83 at S4. Results showed that between S1 and S4, 73.5\% (61/83) horses remained in the same egg shedding category and $94.0 \%(78 / 83)$ in the same treatment category. For horses that did not receive anthelmintic $(n=304), 90.4 \%(225 / 304)$ remained in the same egg shedding category. Horses under 5 years-old were more likely to change egg shedding (odds ratio, OR 3.3, 95\% CI: 1.22-8.46) and treatment (OR 2.8, 95\% CI: 1.1-6.3) categories compared to older horses. These results suggest a high level of consistency in strongyle egg shedding in individuals within one season, and withholding anthelmintics from horses with negative or low (i.e. $<50 \mathrm{epg}$ ) FEC does not appear to be associated with significant increases in egg shedding. Keywords: Horse, Cyathostomins, Strongyle egg shedding, Targeted anthelmintic treatment 


\section{Introduction}

Anthelmintic resistant nematodes pose a threat to equine health and welfare.

39 Targeting anthelmintic treatments to individual horses based on levels of nematode

40 egg shedding is proposed to achieve control, whilst reducing anthelmintic use and

41 selection for resistance. Helminth parasites are typically overdispersed in their hosts:

42 i.e. relatively few individuals within populations are infected with the majority of the

43 associated parasite population [1-4]. Strongyle nematodes in the large intestine are the

44 most important equine parasites and have a high prevalence [5]. Overdispersion has

45 been demonstrated for strongyle faecal egg counts (FEC) in horses, with most

46 individuals shedding relatively low numbers of eggs [6-8]. This overdispersion

47 underpins the rationale behind targeted anthelmintic treatment strategies [5, 9-10],

48 whereby only horses identified as shedding above a specific threshold of eggs

49 (typically $\geq 200$ eggs per gram (epg)) are recommended for treatment. Several studies

50 have shown consistency in strongyle egg shedding patterns in individuals over time

51 [7, 11-14], which could further enhance efficient targeting of anthelmintic treatments

52 and reduce the required frequency of FEC testing. The aim here was to investigate

53 strongyle egg shedding consistency in populations of horses in the UK that followed a

54 targeted anthelmintic treatment programme, with a focus on horses identified as low

55 strongyle egg shedders $(<50$ epg), to examine whether non-treatment of these

56 individuals was associated with increases in egg shedding levels over time. This study

57 also analysed factors associated with shedding consistency in individuals within these

58 populations. A longitudinal cohort study design was used. 


\section{Materials and methods}

\subsection{Study population}

During 2010-2012, 573 horses from 26 equine holdings (yards) in Scotland and

England were recruited (see supplementary data). The number of individual's resident

64

65

66

67 yard was supplied with a questionnaire to provide information on the demographics

83 (i.e. yard function, number of horses etc.), anthelmintic usage (frequency of treatment, 84 last product used, type of deworming programme followed) and general management 
85

86

practices. Yard managers were asked to supply the age of the horses included in the study, but not specific details on breed and sex. On all yards, the manager was the point of contact and was responsible for completion of the questionnaire, coordinating sample collection and postage, and administering anthelmintic treatments.

\subsection{Targeted treatment protocol}

Horses that were previously treated with anthelmintic were sampled after a minimum period of 18 weeks had elapsed after administration of moxidectin, or 14 weeks for ivermectin. The first sample (Screen 1, S1, n=573) was collected between February and March. Horses with FEC $\geq 200$ epg were treated with pyrantel embonate following the manufacturer's instructions (Strongid- $\mathrm{P}^{\mathrm{TM}_{\mathrm{a}}}$ at a dose rate of $19 \mathrm{mg} / \mathrm{kg}$ bodyweight). All horses were FEC screened 8-10 weeks later: this was based on a 6week strongyle egg reappearance period (ERP) for pyrantel embonate $[15,16]$, plus an additional two weeks (Screen 2, S2; May/June, $n=468$ ). Horses with FEC $\geq 200$ epg at S2 were treated with ivermectin $\left(\right.$ Eqvalan $^{\circledR}$ oral paste for horses $\left.{ }^{\mathrm{b}} ; 0.2 \mathrm{mg} / \mathrm{kg}\right)$. All horses were screened 10-12 weeks later based on an ivermectin strongyle ERP of 8-10 weeks [15], plus two additional weeks (Screen 3, S3; August/September, $\mathrm{n}=417$ ). At this point, horses with a FEC of $\geq 200$ epg were treated with moxidectin (Equest ${ }^{\circledR c} ; 0.4 \mathrm{mg} / \mathrm{kg}$ ). On some yards a fourth screen (S4; October/December, $\mathrm{n}=83$ ) was performed on horses that had not received anthelmintic treatment following S3.

\subsection{Sample collection and faecal egg count methodology}

Samples were collected from freshly passed faeces and placed into individually labeled zip-lock bags. Yard managers were provided with instructions on how to collect, store and post the samples, and were asked to collect at least three boli from 
110 freshly voided faeces and to place these into the bag, expelling air before sealing. The

111 samples were sent immediately to the Moredun Research Institute and stored at

112 approximately $4^{\circ} \mathrm{C}$. All samples were processed within 4 days of excretion to reduce

113 the effect of egg degradation [17]. A modification of the salt flotation method (1.2

114 specific gravity) with a detection limit down to 1 epg was used [18]. All samples were

115 analysed in duplicate by taking two $10 \mathrm{ml}$ aliquots from a $100 \mathrm{ml}$ dilution of a well-

116 mixed $10 \mathrm{~g}$ sub-sample and an average taken to estimate the epg count.

118 2.4. Data analysis

119 2.4.1. Egg shedding and anthelmintic treatment categories

120 Each FEC data point on each screening occasion (S1, S2, S3, S4) was assigned a 121 shedding category: 1 (0-49 epg); 2 (50-99 epg); 3 (100-199 epg); 4 (200-299 epg); 5

122 (300-399 epg); 6 (400-499 epg) and 7 (>500 epg). Each FEC data point was also 123 assigned a treatment category: $<200$ epg ( 0 , no treatment) or $\geq 200$ epg (1, 124 treatment).

2.4.2. Egg shedding consistency

127 To assess shedding consistency, the rank change in shedding category between S1 and 128 S2, S1 and S3 and S1 and S4 was calculated. For example, if the category was ranked 129 as 1 for S1 and 6 for S2, the rank change would be 5. Conversely, if the category was 130 measured as 6 for S1 and 3 for S3, the rank change would be -3 . If the category 131 remained the same, rank change assigned was 0. 


\subsubsection{Anthelmintic treatment consistency}

134 Treatment category consistency was determined across S1 and S2, S1 and S3 and S1

135 and S4. If an individual's FEC changed from $<200$ epg to $\geq 200$ epg between two 136 sampling points, the rank assigned was 1 . If it changed from $\geq 200$ epg to $<200$ epg, 137 it was assigned as -1 , and if it remained above or below the 200 epg threshold, was 138 assigned 0.

\subsubsection{Egg shedding and treatment consistency analysis}

141 For each sampling occasion, the number and percentage of horses in each shedding

142 and treatment category were calculated. Further, the number and percentage of horses

143 that were in each rank change category of shedding (-6 to 6$)$ and treatment $(-1,0$ or 1$)$

144 between S1 and each subsequent screening occasion was calculated. To test if there 145 was a significant difference $(p<0.05)$ in the proportion of horses falling into each 146 shedding and treatment category between screening occasions, a binomial test was 147 performed using the prop.test function in RStudio. All analyses were performed in 148 RStudio, version 2.15.1 (The R Foundation for Statistical Computing, 2012). The 149 analysis that was applied to the anthelmintic-treated horses was applied to horses that 150 had not received anthelmintic during the study to assess if no treatment was 151 associated with lower shedding consistency and rising FEC over time. All horses 152 included in this analysis had FEC $<200$ epg at S1.

$154 \quad$ 2.4.5. Factors affecting egg shedding and anthelmintic treatment consistency

155 The effect of age, last anthelmintic administered and number of weeks after the 156 expected ERP of each anthelmintic on the likelihood of a horse changing shedding or 

[22].

The probability of a change in egg shedding and treatment category was estimated using Equation 2.

$$
\mathrm{P}=\exp \left[\beta_{0}+\beta_{1} X_{0}+\ldots+\beta_{k} X_{k}\right] /\left(1+\exp \left[\beta_{0}+\beta_{1} X_{0}+\ldots+\beta_{k} X_{k}\right]\right)
$$

Regression models were initially populated with all potential explanatory variables (age category, last treatment, time in weeks since expected ERP elapsed, Table 1), then variables with the highest, non-significant $p$-values removed in a stepwise process until a model with only significant terms remained. The effect of removing factors from the model was evaluated using log-likelihood ratio tests (LRT) $[19,20]$. $P$-values (Wald) of $\leq 0.05$ indicated factors that had a significant influence on changing shedding or treatment category in the final model. The Hosmer-Lemeshow test [21] was used to assess overall model fit using the 'ResourceSelection' package 
180

181

182

183

184

185

186

187

188

189

190

191

192

193

194

195

196

197

198

199

200

201

202

203

204

\section{Results}

3.1. Consistency of strongyle egg shedding and treatment with anthelmintic

At S1, 70.0\% (401/573) of horses were shedding less than 50 epg (Figure 1a). This level of shedding was not significantly different at S2 $(65.0 \%, 304 / 468)$ and S3 (66.2\%, 276/417), with the proportions in shedding categories 2 and 3 also not significantly different compared to S1. The percentage of horses in category 7 was low compared to the percentage of horses in category 1 : for example, $5.8 \%(33 / 573)$ at $\mathrm{S} 1$ and $0.0 \%(0 / 83)$ at $\mathrm{S} 4$. On each occasion, the percentage of horses in the "no treatment' category ranged from $83.6 \%(479 / 573)$ at $\mathrm{S} 1$ to $91.6 \%(76 / 83)$ at $\mathrm{S} 4$ (Figure 1b).

\subsection{Egg shedding and treatment consistency}

Most horses remained in the same egg shedding and treatment category over time (Figure 2a). From S1 to S2, 61.5\% horses (288/468) remained in the same shedding category; from S1-S3, 58.3\% (243/417), and from S1-S4, 73.5\% (61/83). Between S1 and S2, $16.6 \%(77 / 468)$ horses moved to a lower shedding category and $22.0 \%$ (103/468) to a higher shedding category. Between S1 and S3, 23.7\% (99/417) moved into a lower shedding category and 18.0\% (75/417) moved into a higher shedding category. Between S1 and S4, 14.5\% (12/83) horses moved into a lower shedding category and $8.3 \%(10 / 83)$ individuals moved to a higher shedding category. Between S1 and S2, S1 and S3 and S1 and S4, 81.8\% (383/468), 82.7\% (345/417) and $94.0 \%(78 / 83)$ horses remained in the same treatment category, respectively (Figure 2b). The egg shedding consistency in a sub-group that did not receive anthelmintic during the entire study $(n=304)$ was investigated. The proportion of 
205 horses shedding < 50 epg at S1 was 97.3\% (296/304), at S2, 84.9\% (258/304) and at

206 S3, 85.5\% (213/249). The change in proportion of horses shedding $<50$ epg was

207 consistent throughout the study $(p>0.05)$. Between S1 and S2, 92.1\% (280/304)

208 horses remained in the same shedding category, $0.3 \%(1 / 304)$ were in a lower 209 shedding category and 7.9\% (23/304) in a higher shedding category. Between S1 and

210 S3, the percentage of horses that remained in the same shedding category was $90.4 \%$

$211(225 / 304)$ and the percentage of horses that were in a higher shedding category was

$2129.6 \%(24 / 304)$.

213

3.3. Factors associated with changing strongyle egg shedding category or treatment category over time

216 Only horses $(n=346)$ for which information on age and last anthelmintic treatment

217 were available were included in these analyses. Factors affecting the likelihood of a 218 horse changing egg shedding category were investigated (Model 1). In the final 219 model, age (young horses $\geq 2-<5$ years) and last treatment with moxidectin were 220 identified as significant explanatory variables (Table 2). Young horses $(\geq 2-<5$ 221 years) were more likely to change strongyle egg shedding category compared to foals 222 ( $<2$ years), adult horses $(\geq 5-<18$ years) and geriatric horses $(\geq 18$ years, OR $=3.3$, $22395 \% \mathrm{CI}=1.22-8.46, p=0.02$ ), while horses that had received moxidectin at the last 224 anthelmintic treatment were less likely to change strongyle egg shedding category 225 compared to those that received ivermectin or pyrantel $(\mathrm{OR}=0.15,95 \% \mathrm{CI}=0.05-0.17$, $226 p<0.0001)$. Factors affecting the likelihood of a horse changing treatment category 227 between S1 and S3 were also investigated (Model 2). In the final model (Table 2), 228 young horses $(\geq 2-<5$ years) were more likely to change treatment category 229 compared to foals ( $<2$ years), adult horses ( $\geq 5-<18$ years) and geriatric horses $(\geq 18$ 
230

231

232

233

234

235

236

237

238

239

240

241

242

243

244

years, $\mathrm{OR}=2.8,95 \% \mathrm{CI}=1.1-6.3, p=0.03)$ and horses that received moxidectin as their last treatment were significantly less likely to change treatment group compared to horses that received ivermectin or pyrantel $(\mathrm{OR}=0.15,95 \% \mathrm{CI}=0.1-0.4, p<0.0001)$.

\section{Discussion}

Knowledge that horses shed strongyle eggs at consistent levels over time can help underpin evidence-based targeted treatment control programmes [23]. Currently, FEC-directed targeted treatment programmes are recommended for adult horses, whereby individuals are screened for strongyle egg shedding every 4-6 weeks during the grazing season, and those excreting $\geq 200 \mathrm{epg}$ treated with anthelmintic [10]. Here, strongyle egg shedding in horses, analysed over three to four sampling occasions within a grazing season, was found to be consistent. These results agree with those of previous studies which sampled horses over longer periods (1-3 years) [12-14] and shorter periods [11]. Each of these studies reported a high level of shedding consistency in horses sampled from the general population. One study reported that, if the first two FEC were 0 epg, there was an $82 \%$ probability that the third FEC would be 0 epg and a $91 \%$ chance that it would be $<200$ epg. Additionally, these authors found that if the first two counts were $<200$ epg, there was an $84 \%$ chance that the next FEC would be $<200$ epg, and if the first two FEC were $\geq 200$ epg, there was a $59 \%$ probability that the next FEC would be $\geq 200$ epg [12]. This latter study demonstrated that egg shedding was consistent over a longer sampling period compared to that of the current one, particularly in horses that were measured as shedding 0 epg at the start. In a later survey [13], which followed a similar sampling time frame to ours, horses were treated with anthelmintic when the FEC was measured as $\geq 250$ epg and only data from horses that did not receive anthelmintic 
were analysed. The authors reported that if the first two FEC were 0 epg, there was a $62 \%$ probability that the maximum FEC of the next seven samples would be 0 epg, and if the first two FEC were 0 epg, there was an $88 \%$ probability that the maximum FEC of the next seven counts would be $<200$ epg. The authors concluded that, for individual horses, the magnitude of the initial FEC was significantly positively correlated to the maximal FEC of the subsequent eight counts [13]. In a further study, the repeatability of strongyle egg counts was assessed in naturally infected horses [14]. In that study, samples were collected over nine consecutive months, and analysed using a McMaster method with an egg count detection limit of 20 epg. These authors defined repeatability as the variance between horses divided by the total variance, meaning that a value of 0 indicates no consistency in FEC and a value of 1 indicates perfect consistency. Using raw egg counts (i.e. the number of actual eggs counted before applying the multiplication factor), the within-horse repeatability was 0.52 in all horses and 0.53 when horses that had received treatment were excluded from the analysis [14]. Despite each of the studies described following different counting methodology and distinctive statistical analyses, all demonstrate that strongyle egg shedding in horses was consistent over short and longer sampling timeframes, especially in low egg shedding categories, indicating that such horses tend to excrete low numbers of eggs in the absence of anthelmintic treatment, over a prolonged period. In contrast to these reports, one study examined strongyle egg shedding consistency in ponies managed for conservation purposes, which remained largely untreated with anthelmintic over several years, and found that shedding consistency at individual level was generally weak [7]. In that study, FEC data were analysed using general additive mixed models to estimate repeatability of FEC at individual level and to test for differences in mean FEC amongst populations and age 
280 classes. Climate and season were found to exert a significant effect on FECs 281 measured in individuals in populations that did not receive anthelmintic and a strong 282 interaction was identified between age and climate. The lack of individual consistency 283 observed by Wood et al. (2013) compared with other studies [11-14] could be due to 284 the length of time over which the data were collected, the FEC method used, the 285 absence of anthelmintic treatments, the type of statistical analysis undertaken, or the 286 nature of and level of exposure to parasite infection.

287 Past studies investigating strongyle egg shedding consistency focused on estimates of 288 strongyle FEC using McMaster methods with egg detection limits (dl) between 20 289 and 50 epg [7, 11-14]. In the current study, a more sensitive count method was used.

290 FEC generated using McMaster methods tend to generate higher epg estimates and 291 greater variance. In addition, using a FEC method with a higher egg dl (i.e. 292 multiplication factor), the methodology will be less sensitive to relatively small 293 changes in egg abundance, and larger multiplication factors will artificially inflate 294 variance $[6,24]$. This may potentially lead to lower observed consistency between 295 egg counts from the same individual over time because of the greater degree of 296 artefactual variation in FEC. On the other hand, the higher number of false negative 297 FEC arising from the limited dl of traditional McMaster methods could artificially 298 increase apparent consistency of 0 measured epg over time in low-shedding horses. In 299 the present study, measures were taken to ensure samples were collected, stored and 300 processed in a way to minimise egg degradation [17], to ensure that a representative 301 sample was collected to reduce egg clumping in faeces [10], and to minimise the 302 effects of rounding error by using a very sensitive FEC method. However, the way in 303 which the samples were collected and handled on each yard on each sampling 304 occasion could have impacted the consistency of the results. 
305 Here, egg shedding consistency was higher in adult and geriatric horses compared to 306 youngsters. This lower level of consistency in FEC shedding in younger horses could

307 be related to lower immunity [25] compared with older horses, such that variation in 308 parasite challenge is less buffered and feeds through to downstream variation in FEC.

309 In the current study, horses that were treated with moxidectin prior to the start of the 310 study were less likely to change shedding or treatment category compared to those 311 that had been treated with ivermectin or pyrantel. A likely reason for this is that 312 shedding would be lower in horses previously treated with moxidectin due to its 313 persistent effect against parasites in vivo [26]. Moxidectin has an elimination half-life 314 of 23.11 days compared to ivermectin (4.25 days) and pyrantel (13.43 hours) [26].

315 This means that parasites are exposed to active anthelmintic for longer periods; hence 316 the greater strongyle ERP observed after moxidectin treatment [26]. Moxidectin 317 exhibits higher larvicidal activity compared to the other two anthelmintics. 318 particularly against mucosal larvae [26-28]. This will also affect the strongyle ERP 319 observed after moxidectin administration compared to other equine anthelmintics [26, $32029]$.

321 Recruitment of yards was non-random, being through veterinary practices and the 322 BHS website. Nevertheless, there was heterogeneity in the yards recruited, which is 323 likely to have provided a fairly representative sample of the UK equine population, 324 outside breeding establishments, which have a younger age profile [6]. As such, 325 further research is required to assess consistency of strongyle egg shedding in 326 populations on breeding farms.

327 It should be noted that the FEC data collected here were obtained over a single 328 grazing season, and the effect of season and climate were not accounted for, both of 329 which can impact on strongyle egg shedding patterns [7]. Furthermore, the effects of 
management practices such as removal of faeces from pasture were not investigated,

331 which has been shown to significantly reduce FEC in donkeys that grazed pasture

332 where dung was removed twice-weekly by reducing larval populations on pasture

333 [30]. Long-term studies investigating strongyle egg shedding patterns taking account

334 of season, climate and management practices are warranted as these factors impact the intensity of larval contamination on pasture, which will in turn affect the egg shedding intensity downstream. This will help to better inform FEC-directed targeted

337 anthelmintic treatment programmes, and to understand the appropriate frequency of 338 FEC testing.

339 In conclusion, egg shedding and treatment status at individual level were found to be 340 relatively consistent, especially in adult horses, regardless of whether or not they had 341 been treated with anthelmintic, indicating that horses with negative or low FEC $(<50$ 342 epg) initially were significantly more likely to have low FEC on subsequent 343 occasions, and horses with a high FEC ( $\geq 200$ epg) were significantly more likely to 344 have a high FEC on subsequent occasions. Further, an adult horse not requiring 345 anthelmintic treatment initially (based on a 200 epg threshold), would be less likely to 346 require treatment on subsequent occasions in that season. These findings would 347 suggest that the majority of adult horses are able to regulate their strongyle burden, 348 leading to a maintained low FEC status. There is a lack of published information on 349 long term patterns of strongyle egg shedding in equine populations, especially in 350 horses managed under FEC-directed anthelmintic treatment programmes; this should 351 be assessed in future, particularly in horses that are not receiving regular anthelmintic 352 treatments. 
354

355

356

357

358

359

360

361

362

363

364

365

366

367

368

369

370

371

372

373

374

375

376

377

\section{Acknowledgments}

The authors acknowledge funding from the Elise Pilkington Trust for this study. They are indebted to the yard owners/managers and/or attending veterinary surgeons for the supply of equine faecal samples and to Sheena Tarrant, Emma Wood and Rachel Cookson for help with the FEC analysis.

\section{Manufacturer's details}

${ }^{\mathrm{a}}$ Strongid-P ${ }^{\mathrm{TM}}$ paste, Elanco Animal Health, Basingstoke, Hampshire, UK.

${ }^{b}$ Eqvalan ${ }^{\circledR}$ oral paste for horses, Merial Animal Health, Harlow, Essex, UK.

${ }^{c}$ Equest ${ }^{\circledR}$ Oral Gel, Zoetis UK Limited, Tadworth, Surrey, UK.

\section{References}

[1] Crofton, H.D. (1971) A model of host-parasite relationships. Parasitol. 63, 343364.

[2] Anderson, R.M. and May RM. (1978) Regulation and Stability of Host-Parasite Population Interactions: I. Regulatory Processes. J. Anim. Ecol. 47, 219-247.

[3] Shaw, D.J. and Dobson, A.P. (1995) Patterns of macroparasite abundance and aggregation in wildlife populations: a quantitative review. Parasitol. 111, S111-S133.

[4] Calabrese, J.M., Brunner, J.L. and Ostfeld, R.S. (2011) Partitioning the aggregation of parasites on hosts into intrinsic and extrinsic components via an extended Poisson-gamma mixture model. PloS one. 6:e29215.

[5] Kaplan, R.M. and Nielsen, M.K. (2010) An evidence-based approach to equine parasite control: It ain't the 60s anymore. Equine Vet. Edu. 22, 306-316. 
[6] Relf, V.E., Morgan, E.R., Hodgkinson, J.E. and Matthews, J.B. (2013) Helminth egg excretion with regard to age, gender and management practices on UK Thoroughbred studs. Parasitol.140, 641-652.

[7] Wood, E.L.D., Matthews, J.B., Stephenson, S., Slote, M. and Nussey, D.H. (2013) Variation in fecal egg counts in horses managed for conservation purposes: individual egg shedding consistency, age effects and seasonal variation. Parasitol. 140, 115-128.

[8] Lester, H.E., Spanton, J., Stratford, C.H., Bartley, D.J., Morgan, E.R., Hoddgkinson, J.E., Coumbe, K., Mair, T., Swan, B., Lemon, G., Cookson, R. and Matthews, J.B. (2013). Anthelmintic efficacy against cyathostomins in horses in Southern England. Vet. Parasitol. 197,189-196.

[9] Gomez, H.H. and Georgi, J.R. (1991) Equine helminth infections: control by selective chemotherapy. Equine Vet. J. 23, 198-200.

[10] Lester, H.E. and Matthews, J.B. (2014) Faecal worm egg count analysis for targeting anthelmintic treatment in horses: Points to consider. Equine Vet. J. 46, 139-145.

[11] Dopfer, D., Kerssens, C., Meijer, Y., Boersema, J.H. and Eysker, M. (2004). Shedding consistency of strongyle-type eggs in Dutch boarding horses. Vet. Parasitol. 124, 249 - 258.

[12] Nielsen, M., Haaning, N. and Olsen, S. (2006) Strongyle egg shedding consistency in horses on farms using selective therapy in Denmark. Vet. Parasitol. 135, 333 - 335.

[13] Becher, A.M., Mahling, M., Nielsen, M.K. and Pfister, K. (2010) Selective anthelmintic therapy of horses in the Federal states of Bavaria (Germany) and 
Salzburg (Austria): An investigation into strongyle egg shedding consistency. Vet. Parasitol.171, 116-122.

[14] Scheuerle, M.C., Stear, M.J., Honeder, A., Becher, A.M., Pfister, K. (2016) Repeatability of strongyle egg counts in naturally infected horses. Vet. Parasitol. 228, 103-107.

[15] Borgsteede, F.H., Boersma, J.H., Gaasenbeek, C.P. and van der Burg, W.P. (1993) The reappearance of eggs in faeces of horses after treatment with ivermectin. Vet. Q. 15, 24-26.

410 [16] Mercier, P., Chick, B., Alves-Branco, F. and White, C.R. (2001) Comparative efficacy, persistent effect, and treatment intervals of anthelmintic pastes in naturally infected horses. Vet. Parasitol. 99, 29-39.

413 [17] Nielsen, M.K., Vidyashankar, A.N., Andersen, U.V., Delisis, K., Pilegaard, K., Kaplan, R.M (2010) Effects of faecal collection and storage factors on strongylid egg counts in horses. Vet. Parasitol. 20, 56-61.

[18] Christie, M. and Jackson, F. (1982) Specific identification of strongyle eggs in small samples of sheep faeces. Res.Vet. Sci. 32,113-117.

[19] Zuur, A., Ieno, E.N., Walker, N., Saveliever, A.A. and Smith, G.M. (2009). Mixed Effects Models and Extensions in Ecology with R, Springer. pp. $449-497$.

[21] Hosmer, D.W. and Lemeshow, S. (2005) Assessing the Fit of the Model. In: Applied Logistic Regression, John Wiley \& Sons, Inc. pp. 143-202.

424 [22] Lele, S.R. (2009) A New Method for Estimation of Resource Selection Probability Function. J. Wildlife Man. 73, 122-127. 
[23] Nielsen, M.K., Reinemeyer, C.R., Donecker, J.M., Leathwick, D.M., Marchiondo, A.A. and Kaplan, R.M. (2014) Anthelmintic resistance in equine parasites - Current evidence and knowledge gaps. Vet. Parasitol. 204, 55-63.

[24] Torgerson, P.R., Paul, M., Lewis, M.I. (2012) The contribution of simple random sampling to observed variations in faecal egg counts. Vet Parasitol. 188, 397-401.

[25] Herd, RP. and Gabel, A.A. (1990) Reduced efficacy of anthelmintics in young compared with adult horses. Equine Vet. J. 22, 164-169.

[26] Cobb, R. and Boeckh, A. (2009). Moxidectin: a review of chemistry, pharmacokinetics and use in horses. Parasites \& Vectors 2, S5.

[27] Xiao, L., Herd, R,P., Majewski, G.A. (1994) Comparative efficacy of moxidectin and ivermectin against hypobiotic and encysted cyathostomes and other equine parasites. Vet Parasitol. 53, 83-90.

[28] Schumacher, J. and Taintor, J. (2008) A review of the use of moxidectin in horses. Equine Vet. Edu. 20, 546-551.

[29] Bairden, .K, Davies, H.S., Gibson, N.R. (2006) Efficacy of moxidectin 2 per cent oral gel against cyathostomins, particularly third-stage inhibited larvae, in horses. Vet Rec. 158, 766-768.

[30] Corbett, C., Love, S., Moore, A., Burden, F., Matthews, J., Denwood, M. (2014) The effectivelness of faecal removal methods of pasture management to cpntrol the cyathostomin burden of donkeys. Parasites \& Vectors. 7:48. 
449 Table 1. Variables included in the initial logistic regression model

\begin{tabular}{ll}
\hline Variable & Responses \\
\hline Age category & Foal $(<2$ years), youngster $(\geq 2$ and $<5$ \\
& years), adult $(\geq 5$ and $<18$ years) and \\
& geriatric $(\geq 18$ years). \\
Last anthelmintic class administered & IVM, MOX, PYR \\
Time since expected *ERP elapsed & Weeks \\
\hline Notes: *Egg reappearance period (ERP); ivermectin (IVM); moxidectin (MOX), pyrantel (PYR)
\end{tabular}

450

451

452

453

454 
455 Table 2. Factors significantly affecting the odds of a horse changing egg shedding 456 category (Model 1) and treatment category (Model 2) between sampling occasions S1

457 and S3 as assessed by logistic regression. For each significant variable, the logit 458 coefficient, the standard error (SE), the odds ratio (OR) and associated 95\% 459 confidence intervals $(\mathrm{CI})$, and the significance $(p<0.05)$ are presented.

\begin{tabular}{|c|c|c|c|c|c|c|}
\hline $\begin{array}{l}\text { Model } \\
\left(\mathrm{Fit}^{1}\right)\end{array}$ & $\begin{array}{c}\text { Significant } \\
\text { variable }\end{array}$ & Factor & $\begin{array}{c}\text { Logit } \\
\text { coefficient }\end{array}$ & (SE) & $\begin{array}{c}\text { OR } \\
(95 \% \mathrm{CI}) \\
\end{array}$ & $\begin{array}{c}p \\
\text { (Wald) }\end{array}$ \\
\hline \multirow[t]{3}{*}{$1(0.11)$} & & & 1.44 & 0.27 & $\mathrm{Na}$ & $<0.0001$ \\
\hline & Age & $\begin{array}{l}\text { Youngsters } \\
\text { (2-5 years) }\end{array}$ & 1.20 & 0.55 & $\begin{array}{c}3.3 \\
(1.22-8.46)\end{array}$ & $\begin{array}{c}0.02 \\
(\mathrm{LRT})\end{array}$ \\
\hline & $\begin{array}{l}\text { Last } \\
\text { treatment }\end{array}$ & MOX & -1.90 & 0.31 & $\begin{array}{c}0.15 \\
(0.05-0.17)\end{array}$ & $<0.0001$ \\
\hline \multirow[t]{3}{*}{$2(0.38)$} & & & 1.48 & 0.22 & $\mathrm{Na}$ & $<0.0001$ \\
\hline & Age & $\begin{array}{l}\text { Youngsters } \\
\text { (2-5 years) }\end{array}$ & 1.04 & 0.47 & $\begin{array}{c}2.8 \\
(1.1-6.3)\end{array}$ & $\begin{array}{l}0.028 \\
(\text { LRT) }\end{array}$ \\
\hline & $\begin{array}{c}\text { Last } \\
\text { treatment }\end{array}$ & MOX & -1.89 & 0.61 & $\begin{array}{c}0.15 \\
(0.1-0.4)\end{array}$ & $<0.0001$ \\
\hline es: ${ }^{1}$ & fit was & us & er a & p & $\begin{array}{l}\text { test. } \mathrm{MOX}= \\
\text { atio test. }\end{array}$ & $\mathrm{bx}$ \\
\hline
\end{tabular}




\section{$461 \quad$ Figure Captions}

463 Figure 1. The percentage of horses that fell into each strongyle egg shedding category (1-7)

464 on each screening occasion (S1-S4), with category 1 ( $<49$ eggs per gram (epg) represented by 465 the darkest shade of grey and subsequent categories in lighter shades (A). The percentage of 466 horses that were either shedding $<200$ epg (Category 0 , dark grey) or $\geq 200$ epg (Category 2 ,

467 light grey) as measured by faecal egg count (FEC) on each screening occasion (B). The width 468 of the bars is proportional to the number of observations per screening occasion. No statistical 469 differences $(p<0.05)$ in proportions between screening occasions as determined by the 470 binomial test were observed.

472 Figure 2. The rank change in egg shedding category and treatment category between 473 sampling occasions (S1 and S2, S1 and S3 and S1 and S4). The percentage of horses either 474 remained in the same egg shedding category (0), increased egg shedding category (1 to 6 ) or 475 decreased egg shedding category (-1 to -6$)$, with a rank change in -6 categories represented by 476 the darkest shade of grey and subsequent ascending categories in lighter shades (A). The 477 percentage of horses that were either remained in the same treatment category $(0$, mid-grey),

478 increased in treatment category (1, light grey) or decreased in treatment category $(-1$, dark 479 grey) (B) as measured by faecal egg count (FEC) on each screening occasion. The width of 480 the bars is proportional to the number of observations per screening occasion. There were no 481 statistical differences $(p<0.05)$ in proportions between screening occasions as determined by 482 the binomial test. 